\title{
O dândi vaidoso de Uma história desagradável, de Dostoiévski: aspectos poéticos e tradutórios
}

\author{
Priscila Nascimento Marques ${ }^{1}$
}

\begin{abstract}
Resumo: Opresente artigo aborda aspectos poéticos e da tradução do conto Uma história desagradável, de Fiódor Mikháilovitch Dostoiévski, publicado originalmente em 1862 na revista $\mathrm{O}$ Tempo, e em primeira tradução direta para o português pela Editora 34 em 2016 (DOSTOIÉVSKI, 2016). Inicialmente serão apresentados elementos do enredo e do contexto que circundam a narrativa, particularmente a forte estratificação social russa e o período das reformas do tsar Alexandre II. A seguir, são elencados aspectos poéticos do conto, escolbidos por serem característicos da obra em questão. Em primeiro lugar será comentada a dramaticidade da prosa dostoievskiana, já observada pela crítica (VASSINA, 2008), mas que será complementada e ponderada por uma análise do papel do narrador neste texto. A seguir, serão tratadas a elaboração poética da linguagem (cf. SCHNAIDERMAN, 1982) e o bumor, aspecto menos privilegiados pela crítica do romancista. Por fim, serão comentados alguns momentos da tradução - uso de notas, adaptações e tradução do titulo -, reforçando a ideia de que cada escolha reflete a necessidade de ajustes conforme a lingua de chegada e uma interpretação consistente da obra.
\end{abstract}

Palavras-chave: Dostoiévski, conto, crítica literária, tradução literária.

\section{O conto: texto e contexto}

A literatura russa do século XIX em geral e a prosa de Dostoiévski em particular é povoada por uma série de tipos: o "pequeno homem” (málenki tcheloviék), "homem supérfluo" (líchni tcheloviék), "sonhador" (metchtátel). Em meio à enorme galeria de personagens dostoievskianos, seria possível destacar uma variedade inusitada, mas bastante interessante, que chamarei aqui de "dândi vaidoso". Trata-

1 Pós-doutoranda do programa de Literatura e Cultura Russa, da Faculdade de Filosofia, Letras e Ciências Humanas da Universidade de São Paulo (FFLCH-USP). Mestre e doutora em Literatura e Cultura Russa pela FFLCH-USP. Bolsista Fapesp (processo 2015/17830-1). 
-se de uma figura de origem aristocrática, um alto funcionário que, apesar de seu orgulho e posição social elevada, acaba por se envolver em alguma situação ridícula e vexatória. É o caso do marido ciumento de "A mulher de outro e o marido embaixo da cama" (DOSTOIÉVSKI, 2017); de Piótr Ivánovitch, de "Como é perigoso entregar-se a sonhos de vaidade” (DOSTOIÉVSKI, 2017); e de Ivan Ilitch Pralínski, de Uma história desagradável. O presente artigo se deterá nesse último caso. Incialmente, será feita uma breve contextualização da obra e apresentação do enredo. Em seguida, serão destacados e comentados alguns aspectos poéticos do conto e de sua tradução para o português.

O conto Uma história desagradável foi publicado em 1862 na revisa O Tempo, que era editada pelos irmãos Fiódor e Mikhail Dostoiévski e contava com colaboradores de diversos espectros ideológicos, como os eslavófilos Nikolai Strákhov (1828-1896) e Apollón Grigóriev (1822-1864) e o radical Aleksiéi Rázin (18231875). Com essa formação heterogênea, o periódico participou dos acalorados debates que movimentavam a imprensa russa na década de 1860. A publicação fazia, de modo geral, oposição à revista $O$ Contemporâneo, veículo de orientação mais radical de Nikolai Tchernichévski.

Já em suas primeiras linhas, é possível perceber alusões a acontecimentos fundamentais do contexto social e histórico da Rússia na segunda metade do século XIX. Ainda no primeiro parágrafo, o narrador descreve o momento como sendo de "renascimento da nossa amada pátria e [d]o desejo de todos os seus gloriosos filhos por novos destinos e esperanças" (DOSTOIÉVSKI, 2016, p. 11). O clima de mudanças sociais a que ele se refere, diz respeito às importantes reformas conduzidas pelo tsar Alexandre II nos anos 1860. Os alvos dos novos decretos do autocrata foram a servidão, com a Emancipação dos Servos; o sistema judiciário, com a instituição do tribunal por júri; e a administração regional, com criação dos zemstvos. Tais reformas, contudo, foram de cunho essencialmente administrativo, não político, e visavam à modernização econômica da Rússia, que se encontrava abatida pela derrota na Guerra da Crimeia. Isto é, elas não alteraram a estrutura política da autocracia e modificaram apenas em termos burocráticos a organização do poder; não à toa, resultou em profunda insatisfação e radicalização da ala opositora do governo.

O conto inicia-se com a reunião de três altos funcionários para a comemoração do aniversário de um deles: o conselheiro privado Stepán Nikíforovitch Nikíforov (anfitrião e aniversariante), e os conselheiros efetivos de Estado: Semion Ivánovitch Chipulenko e Ivan Ilitch Pralínski. Reunidos, os altos funcionários discutem, entre outras coisas, sobre o amor à humanidade, ou mais precisamen- 
te, segundo Pralínski, "a humanidade em relação aos subordinados (lembremos que eles ainda são gente)" (DOSTOIÉVSKI, 2016, p. 16), que pode "servir de pedra angular para as futuras reformas e para a renovação das coisas em geral" (DOSTOIÉVSKI, 2016, p. 17). Havia um embate mais explícito entre Pralínski e Chipulenko, pois o primeiro, recém-promovido a general, era um entusiasta da renovação da Rússia, ao passo que o segundo via as reformas com irritação e o falatório de Pralínski com sarcasmo. Para Pralínski, Chipulenko não passa de um reacionário, um tipo ultrapassado, incapaz de acompanhar os novos ventos que sopram na Rússia. Súbito, meio que sem propósito, Stepán Nikíforovitch solta em tom profético e fatalista uma condenação sobre aquele grupo aristocrático: “Não vamos aguentar" (DOSTOIÉVSKI, 2016, p. 17).

Ao final do encontro, Pralínski descobre que seu cocheiro havia desaparecido com sua caleça. Ao invés de castigá-lo fisicamente, como sugere Chipulenko, resolve voltar a pé para casa, de modo a fazer com que o funcionário sinta-se moralmente culpado. No caminho, passa por uma animada festa de casamento. Ao saber que se tratava das bodas de um funcionário do seu departamento, Porfíri Petróvitch Pseldonímov, resolve entrar na festa para cumprir certo "objetivo moral", demonstrar como é generoso e magnânimo e, enfim, fazer uma singela demonstração de amor à humanidade. Pralínski imagina seu ato como uma verdadeira façanha, um grande feito heroico:

Que tipo de heroísmo? Deste tipo. Reflita: considerando as relações atuais entre todos os membros da sociedade, o fato de eu, eu entrar depois da meia-noite no casamento de meu subordinado, de um funcionário do registro que recebe dez rublos por mês, isso sim seria perturbação, um turbilhão de ideias, os últimos dias de Pompeia, o caos! Isso ninguém compreenderá. Stepán Nikíforovitch morreria e não compreenderia. De fato, ele mesmo disse: não vamos aguentar. Sim, mas isso são os senhores, pessoas velhas, paralíticas e inertes, mas eu a-guen-ta-rei! Transformarei o último dia de Pompeia no mais doce dos dias para o meu subordinado, transformarei uma atitude selvagem em uma atitude normal, patriarcal, moral e elevada. Como? Assim. Tenha a bondade de ouvir... (DOSTOIÉVSKI, 2016, p. 25).

A seguir, Pralínski imagina em tons épicos toda a cena que está prestes a acontecer, descreve sua atitude magnânima, a estupefação que acometerá todos os presentes e o senso de hierarquia que não irá se desfazer em absoluto: "Com delicadeza, lembrarei que entre eles e mim existe uma diferença. Como entre o céu e a terra [...] No dia seguinte minha façanha já será conhecida na repartição" (DOSTOIÉVSKI, 2016, p. 27). Essa passagem põe a nu a desmedida vaidade e 
egocentrismo de Pralínski, e revela suas ambições íntimas. Ele aparece, assim, como uma espécie de símbolo e caricatura das reformas realizadas por Alexandre II, pois suas atitudes revelam um caráter formal e exterior, que não alteram, mas até reforçam, as estruturas que sustentam o poder estabelecido. A façanha que supostamente serviria para elevar moralmente o subordinado, deve, em última instância, realçar e reafirmar a intransponível diferença entre as partes.

A realidade, não obstante, revelou-se um pastiche do sonho de glória imaginado por Pralínski. Já no primeiro passo, ao adentrar o local da festa, ele pisa numa sobremesa que havia sido deixada no chão para esfriar (uma imagem síntese que antecipa sua presença "estraga-festa"). Os convidados, que dançavam a quadrilha, não notaram sua chegada. Apenas depois de terminada a música, a presença do conselheiro efetivo foi percebida e fez todos recuarem espantados. Pralínski mostra-se bem menos desenvolto do que o fora em sua imaginação e os convidados revelaram total falta de tato para receber tamanha eminência. A única pessoa a demonstrar o servilismo esperado pelo conselheiro foi a senhora Pseldonímova (mãe do noivo), que the trouxe a melhor comida e bebida da festa: "Como são maravilhosas essas velhinhas russas! [...] Animou-nos a todos. Eu sempre amei o povo...” (DOSTOIÉVSKI, 2016, p. 39). Esse é o povo que Pralínski espera: servil e ciente das diferenças hierárquicas.

A surpreendente e inesperada presença do conselheiro efetivo permanece um enigma para os convidados, até que entre eles começa a se espalhar o rumor de que o visitante estava "um tanto alto". O boato teve efeito liberador para o povo constrangido, que retomou a quadrilha. A reação de Pralínski a essa imagem é bastante eloquente: "Eles, que estavam tão recuados, agora se emancipavam de uma vez! Parecia não ser nada, mas essa transformação foi um tanto estranha: era indicativa de algo. Era como se tivessem se esquecido da presença de Ivan Ilitch!" (DOSTOIÉVSKI, 2016, p. 49). O verbo utilizado é bastante significativo, pois remete imediatamente à recente emancipação dos servos (ocorrida em 1861). Embora ali não se tratassem de servos, o emprego do termo revela como a distância que separava as classes elevadas urbanas da imensidão de funcionários de baixo escalão era tão abissal quanto a que existia entre o grande proprietário e seus servos.

Longe de ter cumprido seu objetivo com a visita, Pralínski resolve permanecer para o jantar. A entrada: arenque e vodca. Esta seria a primeira vez que o conselheiro efetivo tomaria a mais russa das bebidas alcoólicas, e o efeito foi imediato e em turbilhão. A descrição que se segue no conto é uma verdadeira anatomia de uma bebedeira. Primeiro, sentiu ódio por todos ao redor, desejou ir-se embora, e teve vergonha por perceber que todos estavam desembaraçados e 
rindo (seria dele?). Depois do ódio e da vergonha, a vodca trouxe coragem, ainda que a consciência não lhe tivesse abandonado. Em seguida, teve vontade de chorar e de fazer as pazes com todos:

Queria abraçar a todos, esquecer tudo e fazer as pazes. Além disso, queria dizer abertamente tudo, tudo, isto é, o quanto ele era uma pessoa boa, ótima, de talentos extraordinários [...] e o principal, como era progressista, com que humanidade era capaz de ser condescendente com todos, até os mais baixos, e enfim, para concluir, queria dizer francamente todos os motivos que o levaram a aparecer na casa de Pseldonímov sem ter sido convidado, beber das garrafas de champanhe e alegrá-lo com sua presença. (DOSTOIÉVSKI, 2016, p. 54).

Retornam os delírios de grandeza sobre como sua inciativa seria acolhida pelos demais e sua grandeza enaltecida aos gritos. Novamente a realidade se revela o avesso grotesco dos devaneios de Pralínski. O único grande talento que revela aos presentes é lançar perdigotos enquanto tenta articular seus discursos tropeçando a cada sílaba. A gagueira alcoólica do conselheiro efetivo vira motivo de chacota generalizada e um redundante fracasso com seu desmascaramento por um dos convidados. Ao acusá-lo de reacionário (mesma acusação feita por Pralínski aos seus colegas conselheiros), o colaborador de um jornal satírico arranca o verniz das boas intenções de Pralínski: "O senhor veio fazer pose e buscar popularidade [...] apareceu para se gabar de sua humanidade! Atrapalhou a alegria de todos. Bebeu champanhe sem se dar conta de como ele custa caro para um funcionário que recebe dez rublos por mês de ordenado" (DOSTOIÉVSKI, 2016, p. 59). O que se segue é o colapso de Pralínski, que cai inconsciente no chão e é levado ao leito nupcial, onde passa a madrugada sofrendo as consequências físicas dos excessos daquela noite e sendo acudido pela servil senhora Pseldonímova.

$\mathrm{Na}$ manhã seguinte, Pralínski se recompõe e retorna à sua casa, de onde não sairia por oito dias, sofrendo de ataques morais, desejando virar monge, aposentar-se, imaginando como a história já teria se espalhado e arruinado sua reputação. Quando resolve voltar à repartição, é surpreendido com uma recepção séria e respeitosa. Recebe o chefe da seção para assinar alguns documentos, entre os quais a petição de Pseldonímov para ser transferido para outro departamento (precisamente o de Chipulenko, que lhe prometera a vaga). Pralínski, com sua recém-conquistada autoconfiança, volta a discursar: "diga a Pseldonímov que não lhe desejo mal, não desejo!... Que, ao contrário, estou disposto até a esquecer tudo o que passou, esquecer tudo, tudo...” (DOSTOIÉVSKI, 2016, p. 75). O chefe de seção reage estupefato ao comentário disparatado, e se retira desajeitadamente 
da sala, reabrindo a ferida do orgulho de Pralínski, que, desejando enterrar-se, olhou-se no espelho e não viu o próprio rosto. Novamente a narração aponta uma dissonância entre o que é expresso verbalmente pelo personagem por meio do discurso direto e o que revela a narração de sua consciência, só que agora com sinais invertidos. A fórmula verbalizada (dita em discurso direto) encontrada por Pralínski para resolver sua situação é "rigidez, só rigidez e mais rigidez!", em oposição ao amor à humanidade inicial. Intimamente, porém, é atravessado por um profundo sentimento de vergonha que o faz concluir com "Não aguentei!" (narração da consciência, e não discurso direto). Assim, a profecia de Stepán Nikíforovitch é retomada e cumprida, e a narrativa tem um desfecho cíclico.

O texto traz à tona a forte estratificação da hierarquia social russa. Os títulos determinam a categoria a que cada indivíduo pertence, a forma de tratamento que deve receber, seu círculo de convívio etc. Pralínski e Chipulenko, por exemplo, são conselheiros efetivos de Estado (equivalente à patente de major-general), pertencem à quarta classe do funcionalismo civil e devem ser tratados por "Vossa Excelência". Nikíforov, por sua vez, é conselheiro privado, funcionário de patente ainda mais elevada. Abaixo deles estão os membros de níveis intermediários, como o chefe de seção Akim Petróvitch e, por fim, os pequenos funcionários, como Pseldonímov. Estão representados ainda estudantes, jornalistas e artistas independentes, que também compõem as camadas sociais mais baixas.

Dessa forma, o conto apresenta um amplo espectro da sociedade russa e suas camadas naquele período. Entre aqueles que ocupam posições mais elevadas não há homogeneidade. Pralínski pretende-se mais progressista e aberto a mudanças, ainda que, como as reformas de Alexandre II, deseje apenas alterações de certo modo superficiais que não modifiquem o (des)equilíbrio de forças e a estrutura de poder, mas, em última instância, os reforce. Chipulenko representa a aristocracia mais tradicional, aquela acostumada ao funcionamento social convencional sem as novas ideologias reformistas. Seu estatuto é reconhecido e compreendido também pelas classes mais baixas (veja-se que é para Chipulenko que Pseldonímov recorre depois do incidente com Pralínski).

O colaborador do jornal satírico representa a juventude radical raznotchintsi, questionadora das autoridades e desmascaradora de supostos progressistas. Entre Pralínski e o colaborador há traços da polêmica dos pais versus filhos, representada pelo romance de Turguêniev, isto é, da geração de intelectuais dos anos 1840 (os pais), com seu refinamento e formação elevada, e a geração seguinte, de 1860, de origem não aristocrática e ideias e planos de ação muito menos sutis. Pseldonímov representa a classe dos pequenos funcionários, elevada à categoria literária como málenki tcheloviék (pequeno homem). Este pretende ajustar-se àquela sociedade, 
sobreviver nela em uma condição o menos indigna possível. A mãe de Pseldonímov aparece como representante do povo simples, generoso, abnegado, servil e consciente das diferenças hierárquicas.

A narrativa apresenta o encontro de dois mundos afastados, que possuem referências, costumes e valores profundamente diferentes. É possível resumir o estranhamento entre esses universos pelas imagens do champanhe e da vodca: cada qual representa um estrato social e, portanto, formas distintas de socialização e de comunhão com o outro. Quando Pralínski, que fora acostumado a socializar com champanhe, resolve ir à festa de seu subordinado, está atendendo ao grande chamado do movimento populista da época para as classes elevadas e intelectuais: "v narod! k narodu?". Trata-se de um movimento que conclamava à ida ao povo (khojdiênie v narod), isto é, a superação do fosso, marca da sociedade russa, que separava essas classes sociais. Pralínski parece ser carregado por esse clamor tão bem-intencionado. Mas na realidade ele é, como revelado pelo narrador, levado por uma estrela (DOSTOIÉVSKI, 2016, p. 28), decerto aquela que ele carrega no peito e que representa sua patente.

\section{Aspectos da poética}

Do estudo do conto que derivou do processo de tradução depreendem-se três aspectos da poética dostoievskiana que se sobressaem na obra em questão: a dramaticidade e o papel do narrador, uso poético da linguagem e humor.

Apesar de não ter escrito teatro, Dostoiévski é um dos autores mais encenados do mundo. Segundo Vássina (2008), há na literatura do romancista uma forte consciência dramática, que funciona como elemento estrutural básico de sua poética. É possível identificar algumas características da composição que atestam essa característica: as personagens e as situações são contrapostas num mesmo lugar e tempo; há uma abundância de encontros inesperados; a ação é concentrada em poucos núcleos, em pontos de catástrofe e em reviravoltas. Ademais, é a ação que define os conflitos, os traços das personagens e domina a estrutura narrativa da obra. As consequências (interiores e exteriores) dos acontecimentos compõem a linha da ação e conferem dramaticidade a ela. Os diálogos são abundantes e extremamente importantes. Há predomínio do tempo presente e a ação ocorre em um ritmo acelerado.

Grossman (1967, p. 37) ressalta que as "cenas tumultuosas, em que participa muita gente, e que parecem abalar toda a construção do romance: reuniões, brigas, escândalos, histerias, bofetadas, crises" são típicas da composição do romancis- 
ta. Para este mesmo crítico, "Tendo conduzido a cena do escândalo ao apogeu, Dostoiévski desvia abruptamente a ação da ocorrência vulgar para o patético e o heroico" (GROSSMAN, 1967, p. 38). Em toda sua obra, é patente a inclinação dostoievskiana pelo excepcional, e Uma história desagradável não é exceção. O conto transita entre o heroico e o patético e apresenta fatos que passam longe do cotidiano vulgar. Em dois momentos o narrador trata os fatos nesses termos: "Mas a desgraça é que aquele era um momento excêntrico" (DOSTOIÉVSKI, 2016, p. 28), quando resolve ir à festa, e "De fato, sua situação se tornou mais e mais excêntrica” (DOSTOIÉVSKI, 2016, p. 50), depois da vodca.

Ao lado desses evidentes elementos de drama, é importante ressaltar um aspecto crucial da narrativa. O drama exterior, que se desenrola pelo embate dos personagens e pelos diálogos entre eles, não se esgota no enredo de Pralínski. A ação ocorre em duplicidade e espelhamento: no nível da consciência e no nível factual. Cada ato do conselheiro é precedido por uma visão interior dele, como a descrição do grandioso impacto que seu aparecimento teria na festa do funcionário Pseldonímov. Ele imagina a cena, os diálogos, ergue suntuosos castelos de ar que se desfazem quando a ação se desenrola na realidade, fora de sua imaginação, fazendo a passagem do épico para o patético e o grotesco. O dispositivo narrativo que possibilita o trânsito entre essas esferas é o narrador onisciente seletivo composto por Dostoiévski. Além disso, devido ao estado alterado de consciência do personagem (sua embriaguez), o narrador é responsável por traduzir o conteúdo disforme dessa consciência em linguagem literária. $\mathrm{Na}$ passagem a seguir, ele faz uma breve digressão a esse respeito e reflete metalinguisticamente sobre sua função:

É sabido que, em um instante, todo um raciocínio se desenvolve em nossas cabeças na forma de alguma coisa como sensações que não se traduzem em linguagem humana, muito menos literária. Mas tentaremos traduzir todas essas sensações de nosso herói e apresentar ao leitor ao menos a essência delas, por assim dizer, o que há de mais indispensável e verossímil nela. Pois muitas de nossas sensações, quando traduzidas para a linguagem comum, parecem absolutamente inverossímeis. É por isso que elas nunca encontram expressão no mundo, mas todos as temos. É claro que as sensações e pensamentos de Ivan Ilitch eram um tanto desconexos. Mas os senhores sabem o motivo. (DOSTOIÉVSKI, 2016, p. 24).

Nesse sentido, verifica-se que a ênfase na consciência dramática da poética dostoievskiana capta apenas um dos aspectos de sua construção estética, cuja compreensão merece ser complementada pelo exame atento da construção 
narrativa, particularmente da figura do narrador, que é tão inconspícua quanto decisiva em sua literatura ${ }^{2}$.

Um segundo aspecto que merece ser destacado foi estudado por Schnaiderman, em Dostoiévski Prosa Poesia (1982), e diz respeito ao uso poético da linguagem pelo romancista. Por função poética, o autor entende, como Roman Jakobson, as situações em que a ênfase recai sobre a combinação das palavras e não apenas no seu significado. O crítico e tradutor destaca "o gosto pelo trocadilho, pelo humor verbal, pela palhaçada em verso" (SCHNAIDERMAN, 1982, p. 115). Há, assim, um Dostoiévski brincalhão, sarcástico, até grotesco.

Em Uma história desagradável essa característica se faz presente, por exemplo, nos nomes de alguns personagens. Pseldonímov, por exemplo, deriva de psevdoním (pseudônimo, em russo); Pralínski, de pralinê; Mlekopitáev, de mlekopitaiuschee (mamífero). Em todos os casos a etimologia dos nomes carrega alusões sobre o próprio caráter dos personagens, além de produzirem um efeito humorístico ${ }^{3}$.

Esse procedimento leva ao terceiro aspecto que pretendemos abordar no presente artigo: o humor em Dostoiévski. Trata-se de um tema pouco abordado pela crítica e que aparece de maneira mais flagrante não apenas neste conto, mas também em O crocodilo, "O tritão" e "A mulher de outro e o marido embaixo da cama". Em tais textos, tem-se desde o humor mais escrachado, até a sátira e a ironia sutil, seja em relação à aristocracia ou à intelligentsia. Em estudo sobre o riso em Crime e castigo, John Spiegel defende que ele pode revelar os sentimentos mais profundos, atitudes ocultas e motivos inconscientes dos personagens. O riso seria, assim, uma ferramenta para comunicar ideias complexas e temas recorrentes de grande importância de uma maneira concisa e econômica (SPIEGEL, 2000, p. 19). A degeneração da atitude de Pralínski, que se pretende heroica e benevolente por meio do cômico e do grotesco, funciona como reforço retórico para o desmascaramento completo e a condenação moral da figura do "dândi vaidoso".

2 Para mais reflexões sobre o papel do narrador em Dostoiévski, ver Ivantchikova (1994), Gigolov (1988), Rosenshield (1978), Marques (2015).

3 Trata-se de um procedimento bastante recorrente na literatura russa em geral e na dostoievskiana em particular, como se verifica no exemplo de Niétotchka Nię̧ânova, que provém de nie (não), zvat (chamar) e simboliza as crianças infelizes, quase anônimas; e Raskólnikov, sobrenome oriundo de raskol (cisão, em russo), termo que alude tanto ao cisma religioso quanto à cisão da consciência que marca este personagem. 


\section{Aspectos da linguagem e da tradução}

Nesta seção serão comentados alguns momentos da tradução do conto. O primeiro ponto diz respeito ao uso de notas de rodapé e paratextos. Durante a preparação do volume, foi decidido, juntamente com a equipe editorial (Alberto Martins e Danilo Hora), que o conto seria precedido por uma "Nota da tradutora", na qual seriam apresentadas algumas informações gerais do contexto russo (a questão das hierarquias e das reformas de Alexandre II), com a intenção de preparar e enriquecer a leitura do texto, além de evitar que ela fosse excessivamente interrompida por informações complementares.

À tradução foram acrescentadas notas para esclarecimento de alguns termos, etimologia dos nomes e traduções de expressões em francês. Optou-se por manter os nomes em suas formas originais e apresentar a etimologia em nota, ao invés de buscar uma tradução para estes, seguindo o padrão das traduções de literatura russa. Quanto ao uso de expressões em francês, além de apresentar a tradução em nota, informou-se adicionalmente a ocorrência da expressão em francês russificado (transliterado para o alfabeto cirílico) ou não. Tal fato foi considerado importante, pois ambas as formas estão presentes no conto, sendo que o registro russificado aparece quando a expressão é empregada por indivíduos de classe mais baixa e o original em francês é empregado apenas por Pralínski, revelando mais uma camada de diferenciação social no nível da linguagem.

Em um determinado momento da narrativa, os convidados discutem sobre o uso inadequado da língua como índice de iletramento e baixa formação intelectual. O primeiro caso apresentado foi vertido como "literatura de acusamento", em referência ao gênero literatura de acusação. No original, tem-se áblitchitelnaia ao invés de oblitchitelnaia literatura, portanto, uma confusão fonética (tônica erroneamente colocada na primeira vogal) e consequentemente ortográfica, um tipo de equívoco comum no idioma russo. Na versão em português, optou-se por não usar a mesma categoria de erro, mas fazer uma equivalência com uma confusão mais comum e plausível no idioma de chegada (troca de sufixos). Adiante, os convidados citam outros casos de deformações da língua cometidos pelo povo simples: nevalid (vertido como "enválido"), ao invés de invalid (inválido); múmer ("múmero"), ao invés de númer (número) e nimo ("deante") ao invés de mimo (diante). Como é possível observar, foram necessárias adaptações para que as deformações soassem factíveis na língua de chegada e mantivessem o efeito de chiste do original.

A discussão sobre a linguagem popular e suas distorções em relação à língua padrão ganha destaque nessa passagem, mas é possível dizer que todo o conto é perpassado por níveis e significados sociais da língua e até por sua articulação com 
o pensamento e a subjetividade. Inicialmente, Pralínski é descrito como bom orador e frasista, alguém que "começou a falar muito e com eloquência de novos temas, os quais assimilou de forma extremamente rápida e inesperada" (DOSTOIÉVSKI, 2016, p. 15). Sua fala afetada revela-se no texto por sílabas separadas, que representam uma fala escandida, cerimoniosa, quase atuada. Com o desenrolar da ação, vemos também a ruína dessa desenvoltura verbal. Mais tarde, as sílabas separadas já não demonstram gravidade, mas a desarticulação e a disfemia produzidas pela embriaguez. O colapso psicológico de Pralínski é também seu colapso verbal.

Como dito anteriormente, em Uma história desagradável, observa-se a existência de dois planos que coexistem e eventualmente se chocam. A ação real é sempre precedida por uma ação imaginada. Pralínski, enquanto caminha a pé pelas calçadas de madeira da periferia de São Petersburgo, fica imaginando as grandes contribuições que sua tese sobre o amor à humanidade oferecerá para a Rússia e, em seguida, devaneia sobre a grande lição de moral que dará ao povo quando decide entrar na festa de casamento de Pseldonímov.

O que plasma formalmente a discrepância entre esses dois planos (do real e do imaginado) é a escolha precisa e minuciosa das palavras. Ao contrário da difundida ideia segundo a qual "Dostoiévski escrevia mal" (BIANCHI, 2008), verifica-se que a linguagem tem um valor estético determinante nas obras do romancista. No caso do presente conto, observamos como o léxico escolhido suaviza, estetiza a realidade, isto é, escancara o abismo entre o mundo da imaginação de Pralínski e o mundo real.

Um exemplo disso é próprio título do conto, skviérni anekdot. $\mathrm{O}$ adjetivo skviérni, pode ser traduzido por "mau, ruim, desagradável, indecente, nojento"; em outras versões, o conto já foi intitulado "Uma história lamentável”, em inglês recebeu os títulos "A nasty story", "An unpleasant predicament", "A most unfortunate incident" e, ainda, "A disgraceful affair”. A opção por "desagradável” nessa tradução seguiu dois critérios: consistência com outras ocorrências de svkiérni ao longo do conto e correspondência com a ideia de linguagem usada em favor da suavização da realidade.

A primeira ocorrência de skviérni é juntamente com o substantivo anekdot e remete imediatamente ao título do conto. Chipulenko, ao ver que a caleça e o cocheiro de Pralínski haviam desaparecido, exclama: "Que história desagradável!" (DOSTOIÉVSKI, 2016, p. 19). A seguir, o adjetivo é empregado por Pralínski ou pelo narrador para descrever: a pessoa e o rosto de Semión Ivánovitch (DOSTOIÉVSKI, 2016, p. 21); a situação desconfortável produzida por sua "invasão" à festa de Pseldonímov e a reação desajeitada dos convidados (DOSTOIÉVSKI, 
2016, p. 31-32); a situação em que vivia Pseldonímov antes do casamento (DOSTOIÉVSKI, 2016, p. 61); as palavras usadas pelo sogro de Pseldonímov no dia do casamento (DOSTOIÉVSKI, 2016, p. 64); e o gosto na boca de Pralínski no dia seguinte (DOSTOIÉVSKI, 2016, p. 72). Em todos os casos, "desagradável” aparece como um eufemismo para um termo mais adequado, ou mais forte, que foi omitido.

Nesse conto, as coisas não recebem o nome que têm: a embriaguez vira "situação excêntrica", o ato de expelir perdigotos enquanto fala torna-se "talento" e o grande vexame de Pralínski é descrito apenas como uma "história desagradável”. Esse procedimento de deslocar a linguagem para maquiar os fatos, dada sua transparência, resulta no reforço da comicidade do texto, além de revelar camadas mais profundas do caráter do protagonista. Explicita-se, assim, o apego do conselheiro efetivo às aparências (apesar da retórica moral e supostamente humanista), sua ligação com um mundo mais sensorial e superficial. O grotesco da realidade fere seu senso estético e sua delicada sensibilidade. A superficialidade de seus sentimentos é revelada, por exemplo, nas seguintes passagens:

Ele se lembrou de como, na época, surgiu-lhe um pensamento: não seria o caso de dar ao coitado uns dez rublos pelo feriado para que se arrume melhor? Mas como seu rosto era tristonho demais e o olhar tão feio que chegava a despertar repulsa, esse pensamento bondoso evaporou-se por si só, de modo que Pseldonímov acabou sem sua gratificação. (DOSTOIÉVSKI, 2016, p. 23)

Pseldonímov, decerto, depois vai se emendar. Falta-lhe, por assim dizer, aquele verniz da sociedade... (DOSTOIÉVSKI, 2016, p. 55)

A generosidade evapora diante da repulsa pelo feio, e o pequeno funcionário, ainda que continue levando uma vida insignificante, precisa necessariamente do verniz que o tornará mais aprazível à sensibilidade refinada. Com a escolha do adjetivo "desagradável", objetivou-se, a um só tempo, transmitir a função eufemística da linguagem em relação ao real, a qualidade superficial do caráter do protagonista e a sutil presença da ironia do autor nesse texto de sátira e crítica mordaz às "boas intenções" reformistas.

\section{Considerações finais}

Buscamos com este artigo fazer uma apreciação do conto Uma história desagradável, a partir da dissecação do enredo, do estudo de alguns aspectos da poética 
dostoievskiana, revelados pela narrativa e de comentários sobre alguns momentos específicos da tradução, a primeira realizada diretamente do russo para o português. As reflexões aqui presentes foram suscitadas pelo processo de tradução e preparação da versão em português. Esse é um processo que requer do tradutor a imersão no universo do material, que envolve a busca de informações sobre o contexto e uma sensibilidade apurada para os procedimentos, estilo e tom do texto. Assim, com este trabalho, tivemos em vista a explicitação e organização das reflexões oriundas da tradução, as quais nortearam a interpretação e embasaram as escolhas feitas. No caso de Uma história desagradável, foi necessário atentar-se ao tom dos personagens, representantes de estratos sociais bastante distintos, e à mordaz ironia que atravessa a voz do narrador e confere um tom satírico tanto às ideias mais pretensiosas quantos aos momentos mais grotescos.

\section{Referências}

BIANCHI, Maria de Fátima. Dostoiévski escrevia mal? Anais do XI Congresso Internacional da Abralic, 2008. Página eletrônica: <http://www.abralic.org.br/eventos/cong2008/ AnaisOnline/simposios/pdf/036/MARIA BIANCHI.pdf $>$. Consulta realizada em 21 de agosto de 2017.

DOSTOIÉVSKI, Fiódor Mikháilovitch. Uma história desagradável. Tradução de Priscila Marques. São Paulo: Editora 34, 2016.

- A mulher de outro e o marido debaixo da cama. In: Contos reunidos. Tradução de Priscila Marques. São Paulo: Editora 34, 2017.

Como é perigoso entregar-se a sonhos de vaidade. In: Contos reunidos. Tradução de Irineu Franco Perpétuo. São Paulo: Editora 34, 2017.

GIGOLOV, M. G. Tipologuiia rasskáztchikov ránnego Dostoiévskogo (1845-1865). In: Dostoiévski: materiali i issliédovaniia. Leningrado: Naúka, 1988, vol. 8, p. 3-20.

IVANTCHIKOVA, E. A. Rasskáztchik v povestvovátel'noi strukture proizvediénii Dostoiévskogo. In: Dostoiévski: materiali i issliédovaniia. São Petersburgo: Naúka, 1994, vol. 11, p. 41-50.

GROSSMAN, Leonid. Dostoiévski artista. Tradução Boris Schnaiderman. Rio de Janeiro: Civilização Brasileira, 1967.

MARQUES, Priscila Nascimento. O narrador de Crime e castigo segundo Gary Rosenshield: o romance polifônico em xeque. Rus - Revista de Literatura e Cultura Russa, v. 6, n. 6, 2015. Página eletrônica: $\leq$ https://www.revistas.usp.br/rus/article/view/108592/106886>. Consulta realizada em 21 de agosto de 2017.

ROSENSHIELD, Gary. Crime and Punishment. The Techniques of the Omniscient Author. Lisse: The Peter de Ridder Press, 1978. 
SCHNAIDERMAN, Boris. Dostoiévski Prosa Poesia. São Paulo: Perspectiva, 1982.

SPIEGEL, John. Dimensions of laughter in Crime and Punishment. London: Associated University Press, 2000.

VÁSSINA, Elena. A poética do drama na prosa de Dostoiévski. Cadernos de Literatura e Cultura Russa. São Paulo: Ateliê Editorial, 2008. 